\title{
Spatiotemporal Heterogeneities and Driving Factors of Water Quality and Trophic State of a Typical Urban Shallow Lake (Taihu, China)
}

\section{Yonggui Wang}

China University of Geosciences

\section{Yanqi Guo (D 1030474343@qq.com )}

China University of Geosciences https://orcid.org/0000-0002-5305-3056

\section{Yanxin Zhao}

Chinese Academy for Environmental Planning

\section{Lunche Wang}

China University of Geosciences

\section{Yan Chen}

Chinese Academy for Environmental Planning

\section{Ling Yang}

China University of Geosciences

\section{Research Article}

Keywords: Lake Taihu, water quality, eutrophication, spatiotemporal heterogeneities, driving factors, urban shallow lakes

Posted Date: November 9th, 2021

DOl: https://doi.org/10.21203/rs.3.rs-988334/v1

License: (c) (i) This work is licensed under a Creative Commons Attribution 4.0 International License. Read Full License

Version of Record: A version of this preprint was published at Environmental Science and Pollution Research on March 15th, 2022. See the published version at https://doi.org/10.1007/s11356-022-185191. 


\section{Abstract}

Water quality deterioration and eutrophication of urban shallow lakes are global ecological problems with increasing concern and greater environmental efforts. In this study, spatiotemporal changes of water quality and eutrophication over 2015-2019 in Lake Taihu, were assessed using the monthly time series of 7 water quality parameters measured at 17 sites. The whole lake was divided into 7 sub-lakes and trophic condition was evaluated by trophic level index (TLI). Taihu had poor water quality overall which was mainly astricted by the total nitrogen (TN) and the total phosphorus (TP) and maintained a lighteutropher state, but it had improved in the last five years. It is found that all nutrient parameters reached relatively higher concentrations in the northwestern and northern Taihu with combined cluster analysis and spatial interpolation methods. Meiliang Bay was the most polluted and nutrient-rich area. MannKendall test highlighted the fact that the TP and chlorophyll-a (Chl-a) concentrations increased significantly while the TN and five-day biochemical oxygen demand $\left(\mathrm{BOD}_{5}\right)$ decreased. The nutrient loading input from the northwestern areas with high human activity and the geomorphological characteristic of the northern closed bays were the main contributors to the spatial heterogeneity in water quality. The main driving force of $\mathrm{N}$ pollution was the declining river inflow $\mathrm{N}$ loading. And $\mathrm{P}$ pollution was affected more by accumulated endogenous pollution, decline aquatic plants area, as well as closely linked with algae biomass. Further water pollution and eutrophication mitigation of Taihu should focus on the limitation of algae and those heavily polluted closed bays.

\section{Highlights}

- Water quality exhibited significant spatial heterogeneity, poor in the northwest but better in the southeast.

- Concentrations of TP and Chl-a were increased significantly for the last five years.

- The main driving force of nitrogen pollution was river inflow.

- Endogenous pollution took responsibility for phosphorus pollution.

- The Chl-a concentration was closely linked with TP and algae biomass.

\section{Introduction}

With the speed-up of industrialization, urbanization and agriculture, abundant industrial, domestic and rural wastewater inflow into urban lakes, accelerating water quality deterioration and eutrophication ulteriorly. Shallow lakes have the characteristics of low water depth with strong hydrodynamic disturbance and intense lake-land, air-water and water-sediment interactions, which makes them more vulnerable to water pollution (Hatvani et al., 2020). Such phenomenon has been found in a lot shallow lakes, such as Lake Erie (North America) (Steffen et al. 2014), Lake Kasimagaura (Japan) (Xu et al. 2010), Lake Victoria(African) (Olokotum et al. 2020)and Lake Chaohu and Taihu (China) (Qin 2020; Zhang and Kong 2015). As shallow lakes usually have the crucial functions of drinking-water source, aquaculture and irrigation, a series of protective programs have been launched to control the decline in 
freshwater quality (Qin 2007; Schindler 2006). China has paid impressive environmental efforts to alleviate water pollution for these three decades and gained certain positive effects in some lake basins (Ma et al. 2020; Qin et al. 2019). However, the water environment of many lakes still has not been fundamentally improved. The root cause lies in that the driving forces of water pollution in different lakes vary with basin natural environment (e.g., geomorphological characteristic of the lake, monsoon), anthropogenic activities (e.g., wastewater effluent, water diversion project, government treatment policy) and also change over time. Therefore, the analysis of spatiotemporal heterogeneity of water quality and eutrophication status of different lakes individually is helpful to identify the main parameters that polluted the water body and distinguish the driving forces of water quality, so as to maintain water environment sustainability according to local conditions.

Lake Taihu (referred to as "Taihu" below), a typical large urban shallow lake, has long been a popular research site in the world due to its frequent water environment deterioration events (Paerl et al. 2011; Qin et al. 2010; Qin et al. 2013). Taihu is the distribution center of a combination of mass point source and non-point source sewage with a complex river network (228 rivers or channels) (Taihu Basin Authority Of Ministry Of Water Resources 2019), which is greatly affected by human activities (Gao et al. 2002; Wang et al. 2019). With intensive treatment after the occurrence of Wuxi water pollution incident of Taihu in May 2007, the water environment quality of Taihu improved apparently. However, the frequency and formation area of cyanobacterial bloom in Taihu seems to have a rising trend since 2015 (Yang et al. 2016; Zhang et al. 2021). So it is necessary to analyze the water quality and trophic state change features of Taihu and judge whether there are any abnormal phenomena after 2015.

Numerous studies have shown that the water quality and eutrophication of Taihu affected by the hydrology, weather condition and the aquatic vegetation multiply (Wang et al. 2019; Wu et al. 2015; Zha et al. 2018). However, some problems and shortcomings in the existing research still need to be addressed. Pats of studies are limited to focus on a certain area of Taihu, such as Meiliang Bay and Wuli Bay (Wang et al. 2019; Wang et al. 2019), and some are limited to analysis of TN, TP concentrations separately(Zhu et al. 2013; Zhu et al. 2021). Earlier studies reveal that eutrophication of Taihu can be managed by limiting the nutrient inputs ( $\mathrm{N}$ or $\mathrm{P}$ ) to the waterbody (Dai et al. 2016; Xie et al. 2017). However, it is difficult to achieve satisfactory effects only by taking this treatment blindly under the new situation, especially since 2015. In other words, it is urgent to identify diverse driving factors of water quality and take corresponding measures nowadays by analyzing more nutrient, physical and ecological water quality parameters (e.g., permanganate index $\left(\mathrm{COD}_{\mathrm{Mn}}\right)$, ammonia nitrogen $\left(\mathrm{NH}_{3}-\mathrm{N}\right)$, five-day biochemical oxygen demand $\left(\mathrm{BOD}_{5}\right)$, secchi disk (SD), Chlorophyll a (Chl-a)) and exploring the pollution situation in different sub-lakes of the whole Taihu in more detail. In light of the above, analyzing longitudinal time series data and contrasting each Taihu sub-lake area horizontally of multiple water quality parameters plus with Trophic Level Index (TLI) are helpful to fill the lack of the previous research.

The primary objectives of this study are as follows: (1) Exploring the temporal and spatial variation characteristics of water quality and trophic state of Taihu from 2015 to 2019. (2) Identifying the main factors affecting the water quality of Taihu and its changing trend. (3) Exploring the inflow rivers 
pollution load, the hydrometeorological conditions, shape of the lake and other factors concerning water quality. These conclusions sever as a theoretical basis for the comprehensive treatment of Taihu in line with seasonal and local circumstances.

\section{Materials And Methods}

\subsection{Study area and data sources}

Taihu $\left(119^{\circ} 52^{\prime} \otimes 120^{\circ} 36^{\prime} E\right.$ and $\left.30^{\circ} 55^{\prime} \otimes 31^{\circ} 32^{\prime} \mathrm{N}\right)$, the third largest freshwater lake in China, is a typical subtropical shallow lake located in the southeastern of the Yangtze River Delta, with a maximum water depth of $2.6 \mathrm{~m}$ and an average water depth of $1.9 \mathrm{~m}$ (Zhang et al. 2014). The Taihu Basin, is one of the most industrialized, urbanized and densely populated areas in China, playing an important role in drinking water supply, flood controlling, tourism supporting and recreation, shipping and aquaculture. The northwest sector of Taihu accounts for $83 \%$ of the total runoff into the lake, and the outflow rivers are concentrated in the southeast sector.

In this study, datasets from 17 sampling sites were divided into 7 regions according to the Taihu Basin Authority of Ministry of Water Resources to analyze the spatiotemporal of water quality of Taihu. The 7 subregions are the Zhushan Bay, Meiliang Bay, Wuli Bay, Gonghu Bay, Eastern Region, Western Region, and Central Region (Fig. 1), respectively. The datasets were collected from 2015 to 2019 on a monthly basis and the monitoring parameters include $\mathrm{COD}_{\mathrm{Mn}}, \mathrm{TN}, \mathrm{TP}, \mathrm{NH}_{3}-\mathrm{N}, \mathrm{BOD}_{5}, \mathrm{SD}, \mathrm{Chl}-\mathrm{a}$. The unit of SD and Chl-a is meter $(\mathrm{m})$ and $\mathrm{mg} / \mathrm{m}^{3}$ separately, and the units of the rest parameters are all $\mathrm{mg} / \mathrm{L}$. Water quality and hydrology data in this paper were obtained from Taihu Basin Ecology and Environmental Science Research Center.

\subsection{Methods For Data Analysis}

After preprocessing the data (outlier detection and filtering of typos), the concentration of each parameter was calculated by the mean values of all sampling sites in its spatial range. According to the characteristics of the natural environment in Taihu Lake Basin, the seasons were divided into spring (March to May), summer (June to August), autumn (September to November) and winter (December to February). The seasonal and annual mean concentration was calculated from the monthly means.

The Single Factor Evaluation method is used to assess the water quality level of each sampling site. The main idea is to compare the monitoring value of each water quality parameter with the standard value of the target parameter according to the Environmental Quality Standard for Surface Water of China (GB3838-2002). After comparing all of the evaluation parameters, the worst water quality parameter level is selected as the level for the entire water body.

The trophic condition of Taihu was assessed by Trophic Level Index (TLI) (China Environmental Monitoring Station, 2001) (Wang et al. 2002). For both qualitative and quantitative aspects, TLI is a 
weighted sum based on the correlations between Chl-a and other four parameters (TP, TN, SD and $\left.\operatorname{COD}_{\mathrm{Mn}}\right)$. The calculation includes Equations (1) - (6) :

$\operatorname{TLI}(\Sigma)=\sum_{\mathrm{j}=1}^{m} W_{j} \times T L I(\mathrm{j})(1)$

$\operatorname{TLI}(C h l-a)=10[2.5+1.086 \ln (C h l-a)](2)$

$T L I(T P)=10[9.436+1.624 \ln (T P)](3)$

$T L I(T N)=10[5.453+1.694 \ln (T N)](4)$

$\operatorname{TLI}(S D)=10[5.118-1.94 \ln (S D)](5)$

$\operatorname{TLI}\left(C O D_{M \mathrm{n}}\right)=10\left[0.109+2.661 \ln \left(C O D_{M \mathrm{n}}\right)\right]$

where, $\mathrm{j}$ present $\mathrm{Chl}-\mathrm{a}, \mathrm{TN}, \mathrm{TP}, \mathrm{SD}$ or $\mathrm{COD}_{\mathrm{Mn}}, \mathrm{TLI}(\mathrm{j})$ is trophic level index of $\mathrm{j}, \mathrm{Wj}$ is correlative weight for each parameter (Chl-a, 0.266; TP, 0.188; TN, 0.179; SD, 0.183; $C_{M n}, 0.183$ ) (Wang et al. 2019). The unit of each parameter is consistent with the description in the preceding text.

The TLI ranges from 0 to 100, with high values representing high eutrophication levels. Trophic status is classified into five grades based on the TLI scores: oligotropher $(T L I<30)$; mesotropher $(30 \leq T L I \leq 50)$; light-eutropher $(50<\mathrm{TLI} \leq 60)$; middle-eutropher $(60<\mathrm{TLI} \leq 70)$; hyper-eutropher $(\mathrm{TLI}>70)$. The trophic status of each sampling site was assessed from the corresponding TLI calculated value, and the TLI value of the whole Taihu is the mean value of all sampling sites.

The spatial distribution of Taihu water environment was drawn by Inverse Distance Weighted (IDW) method using Arcgis software. Hierarchical cluster analysis (HCA) was carried out on the abovementioned divided seven lakes, and the lakes with similar water quality were divided into a group.

The Mann-Kendall (MK) statistical test is selected to analyze the long-term trend of the water quality sequence. MK test, a rank-based non-parametric method, has been widely used for detecting trends in hydrometeorological time series(Ali et al. 2019; Kisi and Ay 2014; Wu and Qian 2017). Comparing to parametric tests, it has no requirements of homoscedasticity or prior assumptions on the distribution of the data sample and is less sensitive to outliers. As the MK test statistic is determined by the ranks and sequences of time series rather than the original values, it is robust when dealing with non-normally distributed data, censored data, and time series with missing values, which are commonly encountered in hydrometeorological time series (Wang et al. 2020; Yue and Wang 2004). Pearson's Correlation Coefficient is used to estimate the correlation between different water quality indexes.

\section{Results And Discussion}




\subsection{Water quality assessment and eutrophication state evaluation of Taihu}

In the China Environmental Quality Standards for Surface Water (GB3838-2002), when the water quality reaches GB Level III, it is deemed as qualified. The mean concentration of $\mathrm{BOD}_{5}, \mathrm{COD}_{\mathrm{Mn}}$ and $\mathrm{NH}_{3}-\mathrm{N}$ for

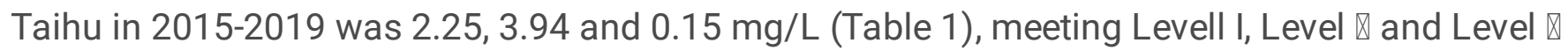
separately. It indicated that the water quality of these three parameters for Taihu was relatively superior. The TP concentration of Taihu reached $0.076 \mathrm{mg} / \mathrm{L}$, belonging to Level $\otimes(0.05-0.1 \mathrm{mg} / \mathrm{L})$, and the TN concentration was as high as $1.589 \mathrm{mg} / \mathrm{L}$, belonging to Level $\otimes(1.5-2.0 \mathrm{mg} / \mathrm{L})$. The data above showed that TN and TP were the principal indexes determining the water quality of Taihu.

Table 1

The average concentration of each water quality parameter in different lake areas from 2015 to 2019

\begin{tabular}{|c|c|c|c|c|c|c|c|}
\hline Lake area & $\begin{array}{l}C_{M n} \\
(m g / L)\end{array}$ & $\begin{array}{l}\mathrm{BOD}_{5} \\
(\mathrm{mg} / \mathrm{L})\end{array}$ & $\begin{array}{l}\mathrm{NH}_{3}-\mathrm{N} \\
(\mathrm{mg} / \mathrm{L})\end{array}$ & $\begin{array}{l}\mathrm{TN} \\
(\mathrm{mg} / \mathrm{L})\end{array}$ & $\begin{array}{l}\mathrm{TP} \\
(\mathrm{mg} / \mathrm{L})\end{array}$ & $\begin{array}{l}\text { SD } \\
(m)\end{array}$ & $\begin{array}{l}\text { Chl-a } \\
\left(\mathrm{mg} / \mathrm{m}^{3}\right)\end{array}$ \\
\hline Zhushan Bay & 4.68 & 3.56 & 0.67 & 3.67 & 0.15 & 0.39 & 23.52 \\
\hline Meiliang Bay & 4.36 & 2.74 & 0.11 & 1.59 & 0.08 & 0.40 & 28.04 \\
\hline Wuli Bay & 4.37 & 3.30 & 0.13 & 1.02 & 0.07 & 0.50 & 26.33 \\
\hline Gonghu Bay & 4.04 & 2.30 & 0.13 & 1.42 & 0.07 & 0.44 & 17.71 \\
\hline Western Region & 4.22 & 2.56 & 0.24 & 2.01 & 0.10 & 0.32 & 21.72 \\
\hline Central Region & 3.79 & 1.93 & 0.10 & 1.48 & 0.07 & 0.34 & 15.51 \\
\hline Eastern Region & 3.31 & 1.56 & 0.07 & 1.12 & 0.05 & 0.37 & 10.58 \\
\hline Taihu & 3.94 & 2.25 & 0.15 & 1.59 & 0.08 & 0.37 & 18.19 \\
\hline
\end{tabular}

During the past five years, the overall proportion of water quality was mainly of Level IV (42.66\%), followed by Level III and Level V, accounting for $31.25 \%$ and $20.73 \%$ respectively (Fig. 2). The proportion

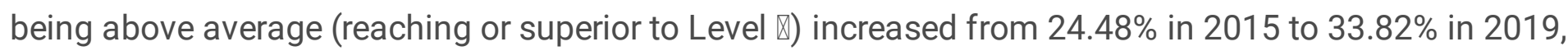
while Level IV reduced by 14 percentage points approximately. The data told us that the water quality of Taihu was generally poor with a slight improvement in the last five years. The proportion of serious pollution (reaching or inferior to Level $\mathrm{V}$ ) increased, rather than declined, reminding us that the water pollution treatment of Taihu still had a long way to go. Taihu had been in a state of lightly eutrophic overall for these years. The mean TLI of Taihu during 2015-2019 was 53.6, with a fluctuation of 53.1 54.6.

Water pollution in different sub-lakes varied greatly. Among 7 sub-lake areas, Zhushan Bay had the worst water quality, whose sum proportion of reaching or inferior to Level $₫$ was up to $90 \%$. The water quality in 
Western Region and Meiliang Bay also was poor, for they both accounted for less than $25 \%$ of the Level IIIII. The Eastern Region had the best water quality. The TLI of each sub-lake was in the order as Zhushan Bay (59.8) > Western Region (56.7) >Meiliang Bay (55.7) >Central Region (53.3) > Gonghu Bay (53.0) > Wulihu Bay (52.7) > 50 (lightly eutrophic) > Eastern Region (49.2). The TLI of Zhushan Bay was significantly higher than that of other sub-lakes and it reached middle-eutropher in nearly half of the observation months, announcing that Zhushan Bay was the focus area affecting the water quality of Taihu.

\subsection{Spatial heterogeneities of water quality and trophic state in Taihu}

\subsubsection{Spatial variation of water quality and cluster analysis of sub-lakes}

Concentration maps were representations of the spatial variability of water quality parameters and TLI and were prepared by spatial interpolation of the five-year mean concentration of 17 sampling sites using the Inverse Distance Weighted (IDW) method (Fig. 3). The water quality of Taihu showed obvious spatial heterogeneity: the concentrations of every parameter (except SD) and TLI were all lower from the northwest to the southeast, indicating that the water quality in the northwestern Taihu was worse than that in the southeast.

SD is an integrated response parameter of lake plankton and both organic and inorganic solutions, reflecting the clarity and turbidity of the lake directly. Low values of SD appeared in the Western Region $(0.32 \mathrm{~m})$ as well as the Central Region $(0.34 \mathrm{~m})$. Due to a large number of rivers with a huge amount of sediment entering the Western Region, the SD value of this area was the lowest. In the Central Region, open lake surface with a higher monthly mean wind speed than that of the lakeshore (Zhang et al. 2003), sediments were easily suspended under the disturbance of wind and flow, resulting in a high concentration of suspended substances in water. So the SD value was low in this area. High values of SD appeared in Wuli Bay $(0.496 \mathrm{~m})$ and Gonghu Bay $(0.44 \mathrm{~m})$.

The seven sub-lakes were divided into three groups basing on the monthly mean concentration of seven parameters by hierarchical clustering analysis ( $\mathrm{HCA})$ (Fig. 3i). Zhushan Bay, whose water quality was the worst, belonging to a single group. The second group contained Wuli Bay, Meiliang Bay and Western Region with poor water quality; The last group was the Eastern Region, Central Region and Gonghu Bay representing better water quality. The clustering result was also consistent with the above conclusions of spatial heterogeneity-the water quality of Taihu improved from northwest sector to southeast.

\subsubsection{Factors Determining Water Quality Spatial Heterogeneity}

The north and northwest of Taihu were the most polluted area. The main reason for this spatial heterogeneity might lie in the pollutant loads of the major rivers around the lake. According to the Health 
Status Report of Taihu Lake (Taihu Basin Authority Of Ministry Of Water Resources 2019), the Huxi Region, including the Western Region and Zhushan Bay, accounted for $68.4 \%$ of the total inflow water of Taihu. Cities along rivers had developed industry and agriculture and high population density with numerous ports, so the pollution load of river inflow was tremendous. Xie (Xie et al. 2017) made statistics on the net pollution load of the Western Region, Zhushan Bay, Meiliang Bay and the Southern Region from 2007 to 2014, finding that the Western Region and Zhushan Bay were the main areas where most pollution remained. The problem of water pollution in Zhushan Bay has existed for a long time due to the external nutrient loading from rivers. After the occurrence of Wuxi water pollution incident of Taihu in May 2007 (Zhang et al. 2010), the gates of Zhihugang and Wujingang, originally connected to Meiliang Bay, were closed, resulting in most of the pollutants diverted to Zhushan Bay (Hu et al. 2010), which greatly affected the water environment of Zhushan Bay, making it the most polluted area with the most serious degradation of lake ecosystem and the highest occurrence of algal bloom in frequency.

To analyze the impact of external pollution source input carrying by the river channel in the north and northwest of Taihu on the lake body scientifically, monitoring sites on estuary were divided according to the location of sub-lakes. Correlation analysis was carried out between the quarterly mean water quality parameter $\left(\mathrm{COD}_{\mathrm{Mn}}, \mathrm{NH}_{3}-\mathrm{N}, \mathrm{TN}\right.$ and TP) concentration in four sub-lakes (Zhushan Bay, Wuli Bay, Meiliang Bay, and Western Region) with the corresponding concentration of inflow river water (Fig. 4). The results showed that the quality parameters concentrations of Zhushan Bay and Wuli Bay were greatly affected by the river inflow. The concentration of $\mathrm{COD}_{M n}, \mathrm{NH}_{3}-\mathrm{N}, \mathrm{TN}$ of the lake water in Zhushan Bay, $\mathrm{COD}_{\mathrm{Mn}}, \mathrm{TN}$, TP in the Wuli Bay, and the TN concentration of the Western Region were significantly related $(p<0.05$ or $\mathrm{P}<0.01)$ to the concentration fluctuation of estuary water.

Therefore, nutrient-rich wastewater from the northern and northwestern regions was the chief reason for serious water pollution in the Western Region, Zhushan Bay, Meiliang Bay. The improvement of water quality of river inflow was the main reason for the promotion of water quality in the north and northwest of Taihu synchronously, and then ameliorate other lake areas and the whole Taihu. The $\mathrm{NH}_{3}-\mathrm{N}_{\text {and }} \mathrm{TN}$ concentrations of the estuary water were much higher than that of the lake water, suggesting that the external input $\mathrm{N}$ loading was the main source of $\mathrm{N}$ pollution in Taihu.

There were many pocket-like bays in the northern and northwestern Taihu. Zhushan Bay, Meiliang Bay and Wuli Bay were all relatively closed waters independent of the big Taihu. These areas received a large amount of sewage from nearby cities like Wuxi and Changzhou, and the pollution load into the lake bay far exceeded their assimilative capacity. The flow movement in the small lake bay was slow and water exchange with big Taihu was blocked due to geomorphology. Under the combined action of these reasons, pollutants in lake bay were not easy to transfer to the open lake area and accumulated in situ. Plus poor self-purification ability, these bays became heavily polluted areas of Taihu. As for the factors affecting the spatial characteristics of $\mathrm{Chl}-\mathrm{a}$, the monsoon must be mentioned. In summer, the southeast monsoon prevailed in Taihu and blew the algae to the northwest, resulting in a higher Chl-a concentration in the northwest. 
In this study, the Chl-a concentration and TLI of Gonghu Bay were relatively low, indicating the water quality was relatively good. The improvement of water quality in Gonghu Bay might be related to Water Diversion from the Yangtze River Project (WDP). Although Gonghu Bay was also a pocket-liked bay, benefiting from the WDP, it had both Yangtze River inflow-whose nutrition concentration (e.g., TP) was lower compared with other major rivers entering Taihu (Zhu et al. 2020)-and channels for outflow, which had a positive effect on the water exchange and alleviating the eutrophication statue (Yan et al. 2011).

According to the results of correlation analysis in Fig. 4, there was no significant correlation between TP concentration of lake water and estuary water in most lake areas, except Wuli Bay. Compared with the other sub-lakes, the area of Wulihu Bay $\left(8.6 \mathrm{~km}^{2}\right)$ was the smallest, even smaller than $1 / 7$ of the second smallest bay-Zhushan Bay $\left(68.3 \mathrm{~km}^{2}\right)$. Wuli Bay extended into the interior of the coastal city Wuxi, with slow water flow, long water exchange cycle and poor water self-purification capacity. Thus, the water quality parameters of Wuli Bay were greatly affected by the river inflow, synchronous fluctuating obviously, especially the TP concentration. This phenomenon showed that the smaller and more closed lake area is more affected by the river inflow pollution.

\subsection{Temporal Trends Of Water Quality In Taihu 3.3.1 Annual dynamic of water quality}

The interannual variation of seven parameters and TLI for Taihu from 2015 to 019 is shown in Fig. 5. Mk test is applied to estimate the long-term variation trend of each parameter on the scale of the whole Taihu and sub-lakes basing on monthly mean concentration (Fig. 6). Results of the MK illustrated that the concentration of $\mathrm{BOD}_{5}(\mathrm{p}<0.05)$ and TN $(\mathrm{p}<0.01)$ of Taihu decreased significantly and the value of TP $(p<0.01), S D(p<0.01)$ and Chl-a $(p<0.05)$ increased notably in the last five years.

The concentration of $\mathrm{COD}_{\mathrm{Mn}}, \mathrm{BOD}_{5}$ and $\mathrm{NH}_{3}-\mathrm{N}$ had always maintained a good state for these years, and all met Level $\mathrm{Q}$ in 2019. Although $\mathrm{COD}_{\mathrm{Mn}}$ and $\mathrm{NH}_{3}-\mathrm{N}$ didn't show significant trends as far as the whole Taihu is concerned, the concentration of these two parameters in more than half of the sub-lakes declined apparently in 2019 comparing with that in 2015 (Fig. 5b). The $\mathrm{NH}_{3}-\mathrm{N}$ concentration in Zhushan Bay showed a remarkable downward trend, dropping from $0.84 \mathrm{mg} / \mathrm{L}$ in 2015 to $0.46 \mathrm{mg} / \mathrm{L}$ in 2019, a dramatic reduction of $45.24 \%$.

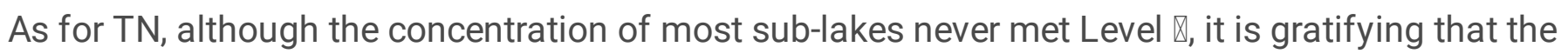
concentration of the big Taihu and six sub-lakes, except Wuli Bay, all had marked downward trends $(p<0.05)$. The TN concentration for Taihu declined from $1.69 \mathrm{mg} / \mathrm{L}$ in 2015 to $1.42 \mathrm{mg} / \mathrm{L}$ in 2019, and all sub-lakes except Wuli Bay had reductions close to or more than $25 \%$. Although TN concentration of Zhushan Bay declined from 4.28mg/L in 2015 to $3.1 \mathrm{mg} / \mathrm{L}$ (inferior to Level $\mathbb{Q}$ )in 2019, its concentration

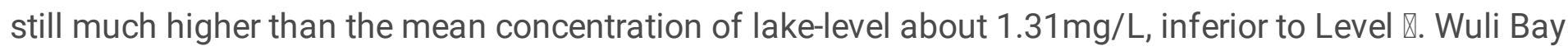
was the only sub-lake where TN concentration increased. 
The TP and Chl-a concentration in Taihu showed significant upward trends as well as in most sub-lakes. The TP concentration of Zhushan Bay was the highest among the seven sub-lakes, and it fluctuated between $0.127-0.176 \mathrm{mg} / \mathrm{L}$, reaching Level $\otimes$ for a long time. And it had the biggest growth rate $(>150 \%)$ of Chl-a in concentration five years. The concentration of TP in Wuli Bay raised from $0.046 \mathrm{mg} / \mathrm{L}$ in 2015 to $0.092 \mathrm{mg} / \mathrm{L}$ in 2019 , with a growth of $100 \%$, and its Chl-a concentration increased by more than $100 \%$.

The SD value in all sub-lakes increased in 2019 comparing to 2015, showing that the turbidity of Taihu decreased and the underwater light environment improved. The TLI in the big Taihu and each sub-lake was relatively stable. Zhushan Bay reached middle-eutropher and the Eastern Region was mesotropher while the rest belong to light-eutropher.

After five years, the concentration of $\mathrm{COD}_{\mathrm{Mn}}, \mathrm{BOD}_{5}, \mathrm{TN}$ and $\mathrm{NH}_{3}-\mathrm{N}$ in Zhushan Lake decreased obviously, and its water quality improvement was the most significant among all sub-lakes. But it is undeniable that it was still the worst area in Taihu. Another area, Wuli Bay, which was usually be neglected, should be paid attention to for its water quality had deteriorated comparing with other sub-lakes.

\subsubsection{Drivers Of Water Quality Long Term Trends In Taihu}

(1) Decline of pollutant concentration in rivers inflow leads the decrease of concentration of $T N, C O D_{M n}$, $\mathrm{BOD}_{5}$ and $\mathrm{NH}_{3}-\mathrm{N}$

In recent years, the concentrations of $\mathrm{COD}_{\mathrm{Mn}}, \mathrm{BOD}_{5}, \mathrm{NH} 3-\mathrm{N}$ and $\mathrm{TN}$ in Taihu reduced in varying degrees (Fig. 5; Fig. 6), which mainly profited from the water quality improvement of rivers inflow. A series of countermeasures aimed at decreasing wastewater effluent discharge and water quality improvement has been implemented, including but not limited to the upgrading and reconstruction of sewage treatment plants in the basin, the shutdown of heavy polluting and substandard enterprises, the construction of high standard farmland, the installation of sewage pipeline network and reduction in the usage of chemical fertilizer (Qin et al. 2019). All these measures made the water quality of the rivers around the lake better and further improved the water environment of Taihu.

Taihu remained light-eutropher stably for recent years. The main reason for TLI changed slightly in the long term was that the value of TN, $\mathrm{COD}_{\mathrm{Mn}}$ and SD alleviated while the TP and Chl-a concentration increased. As a result, the value of TLI remained steadily under the synchronous interaction for improvement and deterioration.

(2) Accumulation of $\mathrm{P}$ loading in sediment and the release of endogenous pollution make TP concentration increase

The TP and Chl-a concentration rebounded since 2014-2015, which was a remarkable phenomenon that had been identified in several latest studies (Wang et al. 2019; Zhang et al. 2021; Zhu et al. 2018; Zhu et al. 2021). Under the condition that the mean TP concentration of the inflow entering the northwestern, 
western and southern Taihu decreased from $0.14 \mathrm{mg} / \mathrm{l}$ in 2015 to $0.12 \mathrm{mg} / \mathrm{l}$ in 2019 year by year (Fig. 4), while the TP concentration in Taihu raised from $0.061 \mathrm{mg} / \mathrm{l}$ in 2015 to $0.081 \mathrm{mg} / \mathrm{l}$ in 2019 (Fig. 5), which was not difficult to draw forth a point of view: the increase of TP concentration in Taihu was mainly due to endogenous pollution. Similar conclusions have been found in other lakes. Lau (Lau and Lane 2002)found that Lake Barton Broad (Norfolk, UK), with a very high reduction (i.e. 90\%) of external $P$ loading, still maintained a high in-lake TP concentration throughout the 11-year period. These observations supported the notion that it was difficult to restore a eutrophic lake solely by nutrient reduction.

The sources of phosphorus nutrients in Taihu consisted of exogenous and endogenous sources. The largest component of the former was the runoff input carrying amounts of pollution load into the lake. The latter mainly came from the release of sediment, decomposition of dead organisms and enclosure aquaculture (Wang et al. 2019). Compared to N, P is more likely to combine with metal ions to form sediments deposited at the bottom of the lake, and the proportion of TP flowing out of the lake is small, so the $\mathrm{P}$ concentration of sediment is always at a high level in the annual accumulation despite the decline of external P loading. The content of nutrients in sediments of Zhushan Bay, Western Region, Meiliang Bay and Gonghu Bay was relatively high (Mao et al. 2020).

(3)Sharp reduction of submerged vegetation area in 2015 reduced the absorption of nutrients

Aquatic plants, a main factor affecting the nutrients release of the sediment, serve to change the quality of lake water, retard stormy waves, immobilize bottom mud, increase water transparency, and suppress the growth and reproduction of algae (Wang et al. 2019). However, the distribution area of aquatic plants of Taihu reduced sharply in 2015, being the smallest in the past decade (Taihu Basin Authority Of Ministry Of Water Resources 2019). The submerged vegetation area in 2013 was $682 \mathrm{~km}^{2}$, while the area in 2016 was only $184 \mathrm{~km}^{2}$ (Table 2). Although the distribution area gradually increased after 2016, the scope has not recovered to half of the largest distribution area in 2013. Wang (Wang et al. 2019) also found this great change by remote-sensing image interpretation, announcing that the high-intensity, largescale, and mechanized salvage of aquatic plants conducted by the local government are the main reason for the sharp decrease of submerged macrophyte. The decrease of submerged vegetation not only reduced the absorption of $\mathrm{P}$ directly but also indirectly inhibit the growth of algae by competing with algae for nutrients (Wu et al. 2021). The effects of these functions were weakened after the sharp reduction of submerged plant area, which led to the increase of Chl-a and TP concentration in the lake. 
Table 2

Changes of submerged vegetation area and cyanobacteria density in Taihu.

\begin{tabular}{|lll|}
\hline Year & $\begin{array}{l}\text { Submerged vegetation } \\
\text { area }\left(\mathrm{km}^{2}\right)\end{array}$ & $\begin{array}{l}\text { Cyanobacteria density } \\
\left(\times 10^{6} \text { cell/L }\right)\end{array}$ \\
\hline 2013 & 682 & 40.1 \\
\hline 2014 & $/$ & 56.6 \\
\hline 2015 & $/$ & 39.2 \\
\hline 2016 & 184 & 82.8 \\
\hline 2017 & 268 & 117.7 \\
\hline 2018 & 284 & 86.2 \\
\hline $\begin{array}{l}\text { Notes: Data obtained from Taihu Basin Authority Ministry of Water Resources. The value of } \\
\text { submerged vegetation area in 2014 and 2015 was lacked. }\end{array}$ \\
\hline
\end{tabular}

(4)Increase of algae biomass contributes to the increase of Chl-a and TP concentration

Chl-a concentration is one of the important indicators to characterize the existing algae biomass (Chen et al. 2007). The relationship between Chl-a and TP concentration is of great significance for understanding the mechanism of lake eutrophication. There is feedback between phosphorus nutrient and cyanobacteria. The rapid growth of cyanobacteria, pumping a large amount of $P$ from the sediment, facilitates the release of $P$ nutrients and increases the $P$ concentration in the lake. This study found that the concentration of Chl-a and TP both increased in the last 5 years, which might assist in explaining that the mounting algae of Taihu affecting the increase of $\mathrm{P}$ concentration. According to the Taihu Lake Health Status Report (Taihu Basin Authority Of Ministry Of Water Resources 2019), the number of cyanobacteria in Taihu increased significantly since 2015 (Table 2). The average density of cyanobacteria in Taihu was 39.2 million / $\mathrm{L}$ in 2015 and reached 82.0 million/L in 2016-2018 with a peak at 117.7 million/L in 2017. Research demonstrated that in the case of the inextricable problem of the high algae biomass of Taihu, TP concentration would still maintain a high level (Zhu et al. 2021).

\subsubsection{Seasonal Variation Of Main Water Quality Parameters In Taihu}

Taihu represented light-eutropher throughout the year with a small seasonal fluctuation of TLI. TLI was higher in spring (54.9) and autumn (53.7), lower in winter (52.9) and summer (52.7). Unlike TLI, the concentration of several water quality parameters showed notable seasonal characteristics (Fig. 7a). The TN concentration was obviously higher in spring and winter, while the TP and Chl-a concentrations were higher in summer and autumn reversely. These observations were consistent with the finding of Wang 
(Wang et al. 2019) and Zha (Zha et al. 2018). The correlation analysis (Fig. 7b) was applied for the seven water quality parameters with two hydrological parameters, water temperature (WT) and water level (Z), basing on the monthly monitoring data of each sampling site to explore the factors influencing seasonal change.

\section{(1)TN concentration}

There was a significant negative correlation between TN concentration and water temperature, and a slight negative correlation between TN and water level. The external input route of $\mathrm{N}$ loading carrying by surface and underground runoff may explain the cause of the above-mentioned feature-the monthly mean TN concentration of Taihu was consistent with that of the estuary water (Fig. 4). On the one hand, the low precipitation and water level in winter condense the $\mathrm{N}$ concentration in the lake; on the other hand, the heavy use of fertilization during the spring cultivation period raises TN concentration. Therefore, for the seasonal pollution prevention of $\mathrm{N}$ of Taihu, attention should be paid to the adjustment of the water level in the dry season and the strict limitation of the input of non-point source $\mathrm{N}$ load.

(2)TP and Chl-a concentration

The inter-relationships between Chl-a and TP and water temperature were highly sensitive to seasonal periodicity (Fig. 7b). May, June and November were the months with large cyanobacteria blooms in Taihu according to the multi-year data of The Health Status Report of Taihu Lake, and these periods corresponded to the high concentration of TP and Chl-a. Chl-a concentration was particularly higher in northern and northwestern Taihu (Meiliang Bay, Wuli Bay, Zhushan Bay and Gonghu Bay) in summer. The potential reasons for such spatial-temporal characteristics might be as follows. For one thing, the water temperature of Taihu was higher in summer and autumn, which was conducive to the growth of algae. For another, algae tend to accumulate in the northwestern areas and windward shores of Taihu owing to the southeast monsoon prevailing in summer, which caused the difference of Chl-a concentration in space. In addition, as a primary producer, the algal biomass and Chl-a concentration in lakes may be more affected by hydrometeorological conditions such as intense rainfall and strong winds than nutrients (Zhu et al. 2018). Therefore, it is necessary to prevent the great impact of hydrological and meteorological conditions on cyanobacteria bloom.

Figure 8 showed the linear correlation between the monthly average concentrations of TP and Chl-a in four sub-lakes. The fitting relationship of Wuli Bay was very good, with $\mathrm{R}^{2}$ up to 0.921 , and other sublakes had poorer curve fitting. This observation illustrated that Chl-a and TP both had a much more tight relationship with each other in relatively closed and small lake bay areas.

(3)SD value

In summer and autumn, the spatial disparity of SD value was unapparent and the SD fluctuating between $0.33 \mathrm{~m}-0.44 \mathrm{~m}$ (Fig. 7). However, in spring and winter, the spatial difference was displayed notably. In the closed lake bay areas (Wuli Bay, Gonghu Bay, Meiliang Bay, Zhushan Bay), the SD values were apparently 
higher than the yearly mean SD value $(0.37 \mathrm{~m})$, while the open areas, such as the Eastern Region, Central Region and Western Region, were lower than mean value. The seasonal variation in different lake areas was related to the seasonal change of wind speed and algae growth in different sub-lakes. For sub-lakes with large area and light eutrophication, the influence of wind on transparency was dominant (Zhang et al. 2003), so the seasonal change of SD values in these areas was small. However, for those eutrophication hardest-hit lake bays, the rapid proliferation of algae in spring and summer led to the decrease of transparency. And in winter, the wind speed and algae area in the lake bays were small, so the SD value rebounded.

\section{Conclusion}

In this study, the spatiotemporal distribution characteristics of the water quality and trophic state in Taihu were analyzed based on the monitoring datasets represented by nutrient, physical and biological parameters and trophic level index (TLI) from 2015 to 2019. The results indicated that Taihu was generally in a state of light-eutropher and the water quality in Taihu these years remained poor, mainly belonging to GB Level $\nabla$. TN (GB Level $\bigotimes)$ and TP (GB Level $\bigotimes)$ were the key parameters determining the quality level.

In terms of spatial heterogeneity, the water quality in northern and northwestern Taihu was worse than that in the southeastern area. And Zhushan Bay was the most serious polluted and eutrophication (middle-eutropher) sub-lake as well as the area with the most obvious improvement in water quality according to the statistical analysis and cluster analysis. For the long-term trends, the value of BOD ${ }_{5}, \mathrm{TN}$ and SD appeared markedly favorable prognosis while the concentrations of TP and Chl-a showed alarming uptrends. The findings in this paper were basically consistent with previously published relevant research results. The river inflow carrying tremendous nutrient-rich wastewater in the northern and northwestern Taihu dominantly caused the spatial heterogeneity of water pollution in Taihu Lake. Besides, the topographic (the shape and area of sub-lakes) and meteorological factors (monsoon direction and wind speed) also contributed to the spatial disparity. Benefited from the reduction of the external input nutrient loading into the lake by comprehensive control measures of Taihu, the $\mathrm{N}$ pollution of Taihu was alleviated. However, the reason for the rebound of the TP and Chl-a concentration might lie in the accumulated pollution loading in the sediment, the sharp decline of the aquatic plants in 2015 and the high algae biomass in the lake. As for seasonal variation, the value of TN, TP, Chl-a and SD in different seasons were impacted by the water temperature, water level, wind speed and the shape of bays, as well as the agricultural activities around the lake and algae reproduction habit.

The present situation of water pollution and eutrophication in Taihu is still grim. TN, TP and Chl-a are three indicators that need considerable attention, especially the close linkage between Chl-a and TP concentration. To better govern water pollution and eutrophication in Taihu, it is necessary to reduce the external nutrients input, endogenous pollution loading and algae biomass. Closed lake bays with serious pollution need more careful treatment according to local conditions. 


\section{Declarations}

Authors Contributions The authors state that they participated in the design of the article prepared in the following way: Y,W: Conceptualization, Writing-Original Draft \& Review \& Editing, project administration. Y.G: Writing - Original Draft \& Review \& Editing, Visualization, Supervision. Y.Z: Resources, Supervision, Funding acquisition. L,W: Writing- Review \& Editing. Y,C: Investigation, Methodology. L,Y: Formal analysis.

Funding This work was supported by the National Nature Science Foundation of China (No. 41807471) and the Open Research Fund Program of MNR Key Laboratory for Geo-Environmental Monitoring of Great Bay Area (SZU51029202010).

Data availability Not applicable

Ethical Approval The authors express their ethical approval of the contents of the submitted work.

Consent to Participate The authors express their consent to have participated in the submitted work.

Consent to Publish The authors state that the data used is in the public domain and may be published.

Competing Interests The authors have no conflicts of interest to declare that are relevant to the content of this article

\section{References}

1. Ali R, Kuriqi A, Abubaker S, Kisi O (2019) Long-term trends and seasonality detection of the observed flow in Yangtze river using Mann-Kendall and Sen's innovative trend method. Water-Sui 9 (11), 1855

2. Chen YG, Liu WL, Han HJ, Hu WP (2007) Relationships between chlorophyll-a content and tn and tp concentrations in water bodies of Taihu lake, China. Chin J. Ecol 12 (26), 2062-2068

3. Dai XL, Qian PQ, Ye L, Song $T$ (2016) Changes in nitrogen and phosphorus concentrations in lake Taihu, 1985-2015. J. Lake Sci 05 (28), 935-943

4. Gao C, Zhu JG, Dou YJ (2002) Contribution of agricultural non-point source pollution to water quality deterioration in tai lake watershed: recent trends and research priorities. Resour. Environ. Yangtze. Basin 03, 260-263

5. Hu KM, Pang Y, Xie F, Jiang Y, Yang ST (2010) Effects of Zhihugang and Wujingang closing sluices on water environment of lake Zhushan, lake Taihu. J. Lake Sci 06 (22), 923-929

6. Kisi O, Ay M (2014) Comparison of Mann-Kendall and innovative trend method for water quality parameters of the Kizilirmak river, Turkey. Journal of hydrology (Amsterdam) (513), 362-375

7. Lau SSS, Lane SN (2002) Biological and chemical factors influencing shallow lake eutrophication: a long-term study. Sci Total Environ 3 (288), 167-181

8. Ma T, Zhao N, Ni Y, Yi J, Wilson JP, He L, Du Y, Pei T, Zhou C, Song C, Cheng W (2020) China's improving inland surface water quality since 2003. Sci Adv 1 (6), eaau3798 
9. Mao XW, Wu HY, Xu F (2020) Analysis of pollution characteristics of main nutrients in Taihu lake sediment. Water Res Prot 4 (36), 100-104

10. Olokotum M, Mitroi V, Troussellier M, Semyalo R, Bernard C, Montuelle B, Okello W, Quiblier C, Humbert J (2020) A review of the socioecological causes and consequences of cyanobacterial blooms in lake Victoria. Harmful Algae (96), 101829

11. Paerl H, Xu H, Mccarthy M, Zhu G, Qin B, Li Y, Gardner W (2011) Controlling harmful cyanobacterial blooms in a hyper-eutrophic lake (lake Taihu, China): the need for a dual nutrient ( $n \& p)$ management strategy. Water Res 5 (45), 1973-1983

12. Qin B, Zhu G, Gao G, Zhang Y, Li W, Paerl HW, Carmichael WW (2010) A drinking water crisis in lake Taihu, China: linkage to climatic variability and lake management. Environ Manage 1 (45), 105-12

13. Qin B, Gao G, Zhu G, Zhang Y, Song Y, Tang X, Xu H, Deng J (2013) Lake eutrophication and its ecosystem response. Chinese Science Bulletin 9 (58), 961-970

14. Qin B, Paerl HW, Brookes JD, Liu J, Jeppesen E, Zhu G, Zhang Y, Xu H, Shi K, Deng J (2019) Why lake Taihu continues to be plagued with cyanobacterial blooms through 10years (2007-2017) efforts. Sci Bull (Beijing) 6 (64), 354-356

15. Qin BQ (2007) Mechanism of occurrence of lake eutrophication in midstream and downstream of Yangtze river and countermeasures for controlling it. Bull. Chin Acad. Sci 6 (22), 503-505

16. Qin BQ (2020) Shallow lake limnology and control of eutrophication in lake Taihu. J. Lake Sci 5 (32), $1229-1243$

17. Schindler DW (2006) Recent advances in the understanding and management of eutrophication. Limnol Oceanogr 1part2 (51), 356-363

18. Steffen M, Belisle B, Watson S, Boyer G, Wilhelm S (2014) Status, causes and controls of cyanobacterial blooms in lake erie. J Great Lakes Res 2 (40), 215-225

19. Taihu Basin Authority Of Ministry Of Water Resources 2019 The health status report of Taihu lake(2018)

20. Wang F, Shao W, Yu H, Kan G, He X, Zhang D, Ren M, Wang G (2020) Re-evaluation of the power of the Mann-Kendall test for detecting monotonic trends in hydrometeorological time series. Frontiers in Earth Science (8), 14

21. Wang H, Chen HX, Xu ZA, Lu BY (2019) Variation trend of total phosphorus and its controlling factors in lake Taihu, 2010-2017. J. Lake Sci 4 (31), 919-929

22. Wang J, Fu Z, Qiao H, Liu F (2019) Assessment of eutrophication and water quality in the estuarine area of lake Wuli, lake Taihu, China. Sci Total Environ Pt 1 (650), 1392-1402

23. Wang M, Zhang JY, Chen QW, Shi WQ, Sun QG (2019) Variations in nitrogen and phosphorous concentrations and major phytoplankton species in the northwestern lake Taihu between 2003-2012. Acta Ecol Sinica 1 (39), 164-172

24. Wang MC, Liu XQ, Zhang JH (2002) Evaluate method and classification standard on lake eutrophication. Environ Monit.China 5 (18), 47-49 
25. Wang S, Gao Y, Li Q, Gao J, Zhai S, Zhou Y, Cheng Y (2019) Long-term and inter-monthly dynamics of aquatic vegetation and its relation with environmental factors in Taihu lake, China. Sci Total Environ Pt 1 (651), 367-380

26. Wu DH, Jia GH, Wu HY (2021) Chlorophyll-a concentration variation characteristics of the algaedominant and macrophyte-dominant areas in lake Taihu and its driving factors, 2007-2019. J. Lake Sci, 1-13

27. Wu H, Qian H (2017) Innovative trend analysis of annual and seasonal rainfall and extreme values in Shaanxi, China, since the 1950s. Int J Climatol 5 (37), 2582-2592

28. Wu T, Qin B, Brookes JD, Shi K, Zhu G, Zhu M, Yan W, Wang Z (2015) The influence of changes in wind patterns on the areal extension of surface cyanobacterial blooms in a large shallow lake in China. Sci Total Environ (518-519), 24-30

29. Xie AL, Xu F, Xiang L, Xu B, Lin LC, Wang CL (2017) Trend analysis for pollutant load of major rivers around Taihu lake and its impact on water quality in Taihu lake. J. Hohai Uni(Natural Sciences) 05 (45), 391-397

30. Xu KQ, Qi LH, Ebie Y, Inamori Y, Sudo R (2010) Measures and policies for lake eutrophication in Japan. China Environ Sci z1 (30), 86-91

31. Yan SW, Yu H, Zhang LL, Xu J, Wang ZP (2011) Water quantity and pollutant fluxes of inflow and outflow rivers of lake Taihu囚2009. J. Lake Sci 06 (23), 855-862

32. Yang Z, Zhang M, Shi X, Kong F, Ma R, Yu Y (2016) Nutrient reduction magnifies the impact of extreme weather on cyanobacterial bloom formation in large shallow lake Taihu (China). Water Res (103), 302-310

33. Yue S, Wang C (2004) The Mann-Kendall test modified by effective sample size to detect trend in serially correlated hydrological series. Water Resour Manag 3 (18), 201-218

34. Zha HM, Zhu MY, Zhu GW, Yang ZS, Xu H, Shen RJ, Zhong CN (2018) Seasonal difference in water quality between lake and inflow/outflow rivers of lake Taihu, China. Environ Sci 03 (39), 1102-1112

35. Zhang HJ, Zhuang Y, Sheng Y, Ji K, Ye L, Chen LZ (2021) Research on the cause of total phosphorus increase in Taihu lake since 2015. Arid Environ Monit 01 (35), 6-9+27

36. Zhang M, Kong FX (2015) The process, spatial and temporal distributions and mitigation strategies of the eutrophi-cation of lake Chaohu(1984-2013). J. Lake Sci, 791-798

37. Zhang Q, Kong M, Tang WY (2014) Water quality assessment in the surface waters from Taihu lake and its main tributaries. Resour.Environ.Yangtze Basin 000 (23), 73-80

38. Zhang XJ, Chen C, Ding J, Hou A, Li Y, Niu ZB, Su X, Xu Y, Edward AL (2010) The 2007 water crisis in Wuxi, China: analysis of the origin. J Hazard Mater 1 (182)

39. Zhang YL, Qin BQ, Chen WM, Hu WP, Yang DT (2003) Distribution, seasonal variation and correlation analysis of the transparency in Taihu lake. Trans. Oceanol. Limnol 02, 30-36

40. Zhu GW, Qin BQ, Zhang YL, Xu H, Zhu MY, Yang HW, Li KY, Min S, Shen RJ, Zhong CN (2018) Variation and driving factors of nutrients and chlorophyll-a concentrations in northern region of lake 
Taihu, China, 2005-2017. J. Lake Sci 2 (30), 279-295

41. Zhu GW, Qin BQ, Zhang YL, Li Y, Zhu M, Xu H, Zhang YB (2021) Fluctuation and future control strategy of phosphorus concentration in lake Taihu in the past 70 years. J. Lake Sci, 1-17

42. Zhu M, Zhu G, Li W, Zhang Y, Zhao L, Gu Z (2013) Estimation of the algal-available phosphorus pool in sediments of a large, shallow eutrophic lake (Taihu, China) using profiled SMT fractional analysis. Environ Pollut (173), 216-223

43. Zhu W, Xue ZP, Zhang YM, Zhai SH, Feng GY, Wang RC, Chen HM, Hu SY, Zhao S, Zhou Y (2020) Effect of water diversion from the Yangtze river to lake Taihu on total phosphorus rebound after 2016. J. Lake Sci 05 (32), 1432-1445

\section{Figures}

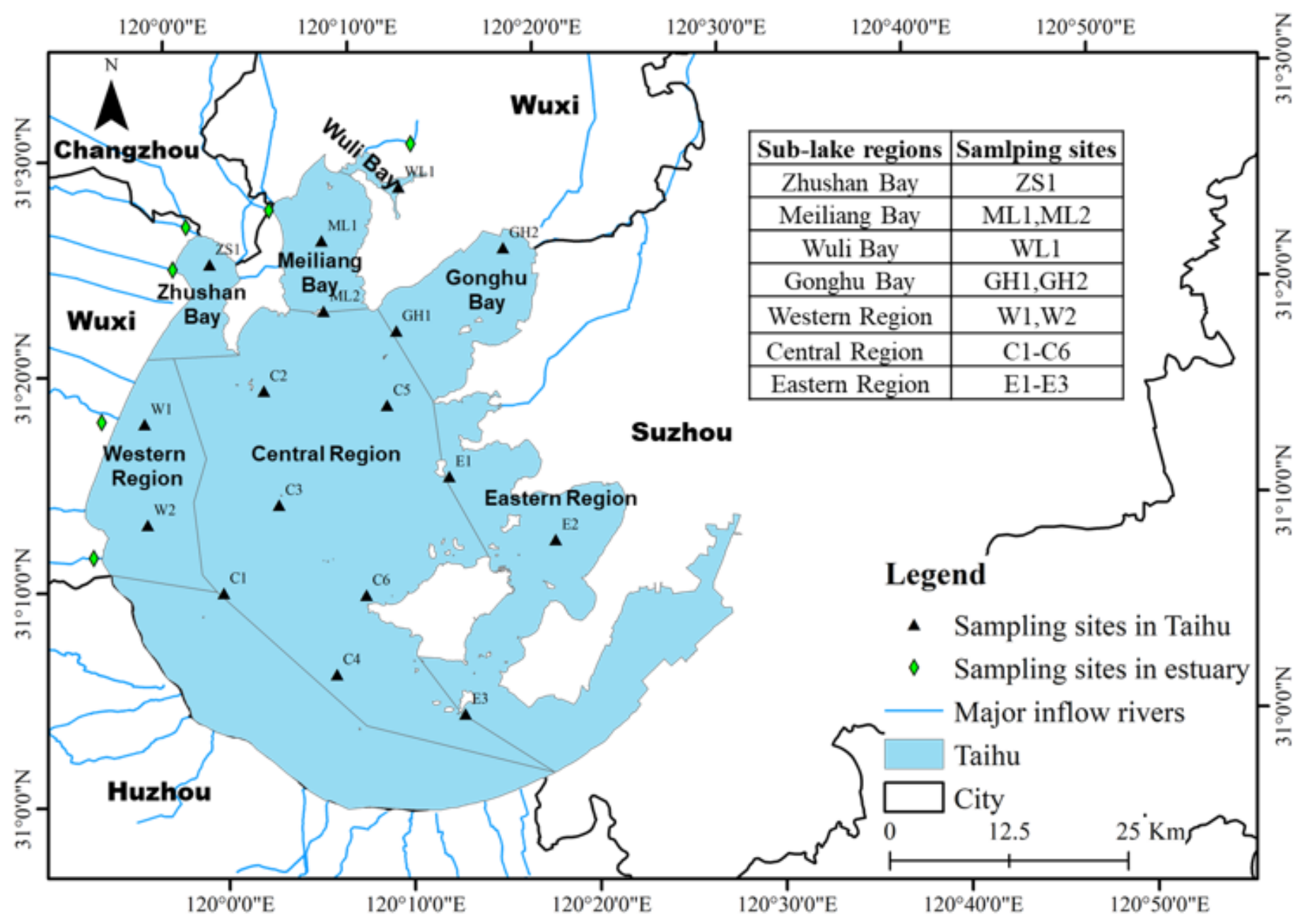

Figure 1

The locations of the sampling sites and the subregions in the Taihu. 


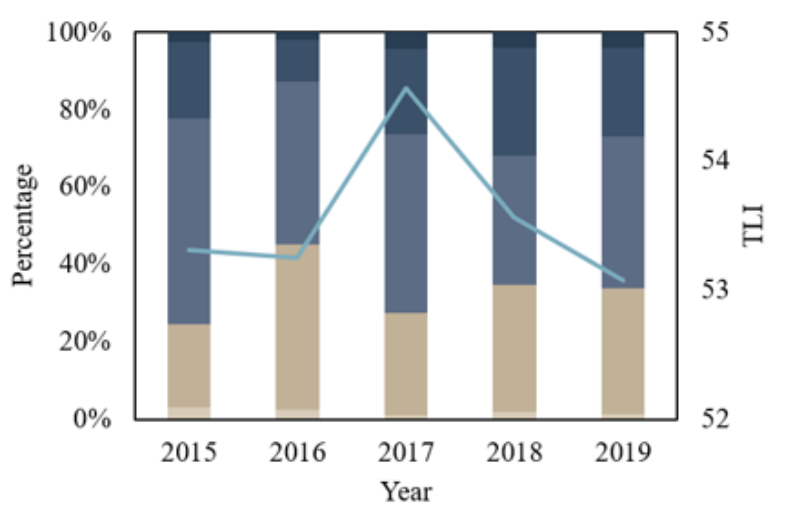

(a)

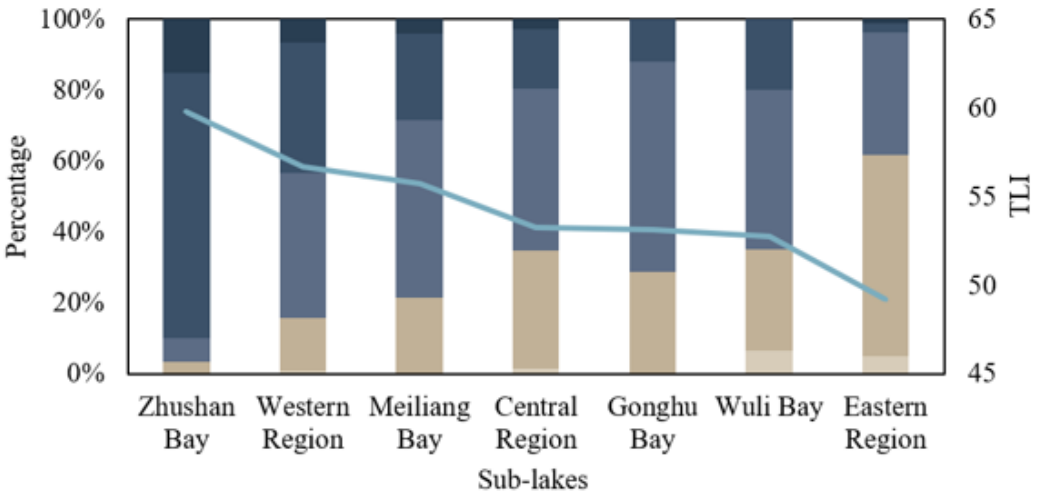

(b)

Leverl II $=$ Leverl III $=$ Leverl IV $\cong$ Leverl V $=$ Inferior to LeverV —TLI

\section{Figure 2}

(a) Annual change of water quality levels proportion and TLI of Taihu in 2015-2019. (b) The total water quality levels proportion and the mean TLI in sub-lakes during 2015-2019. 

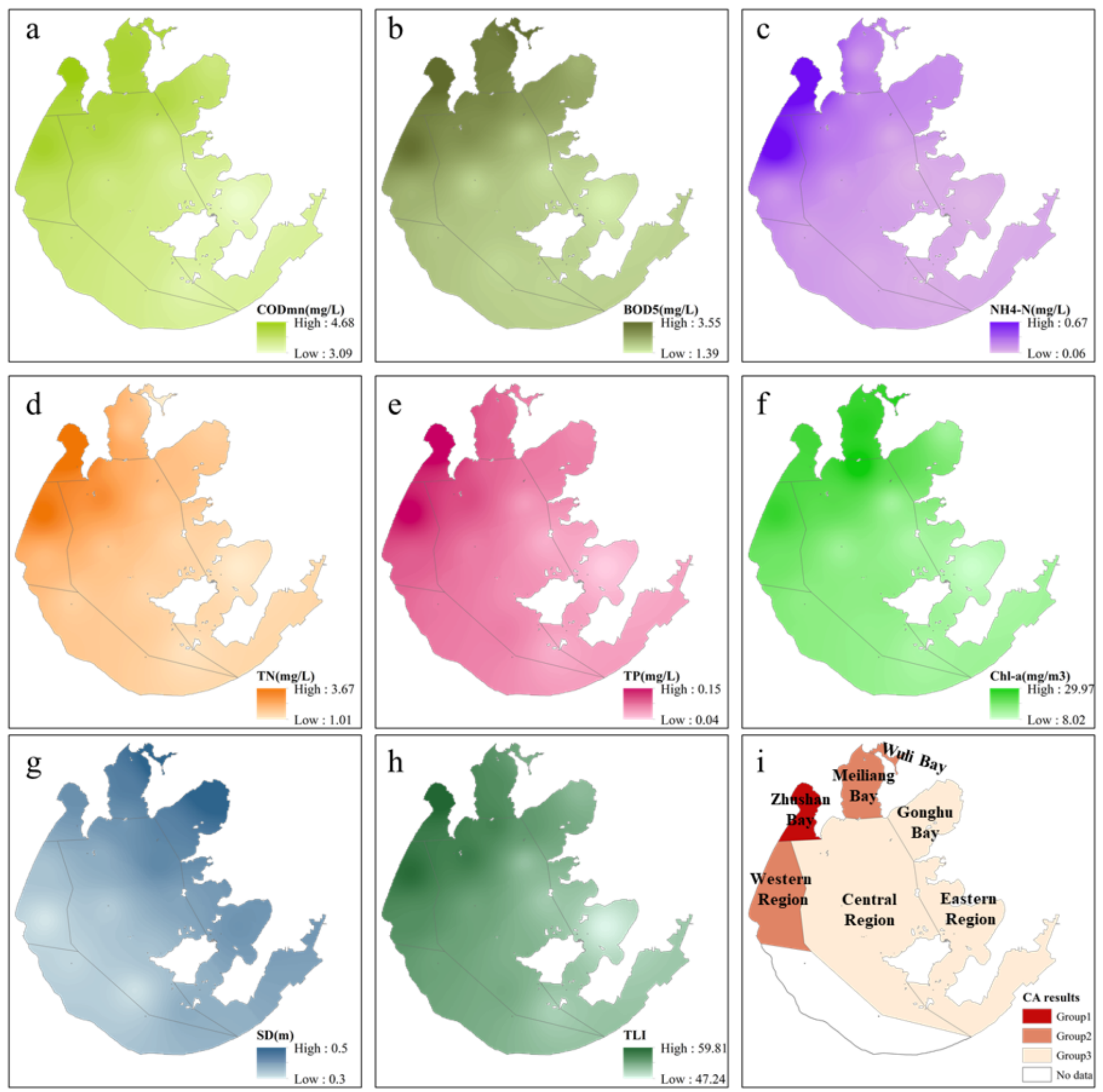

\section{Figure 3}

(a-h) Spatial variation trends of different water quality parameters and TLI of Taihu. (i) Cluster analysis results of seven sub-lakes. 


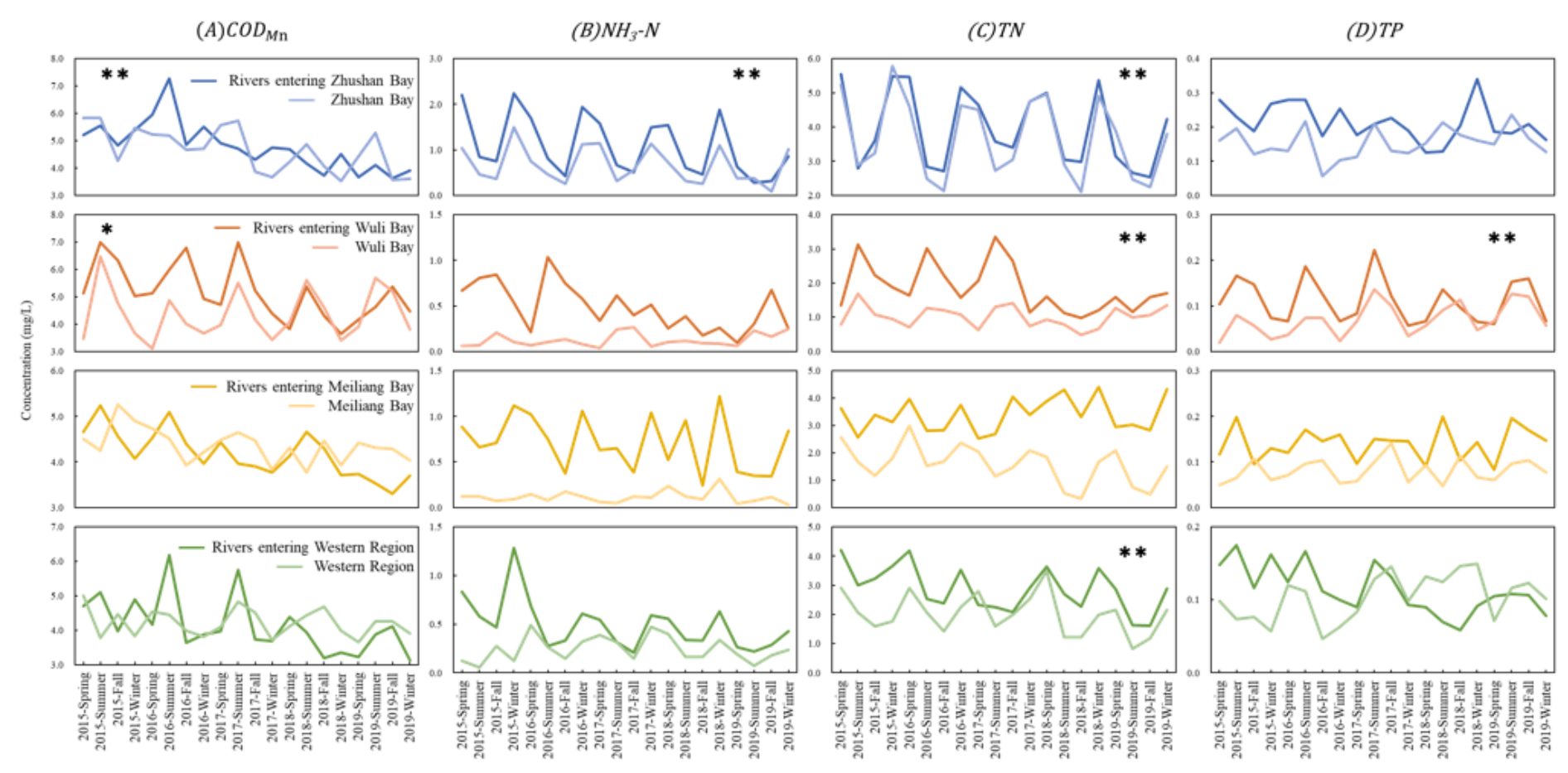

\section{Figure 4}

Observed changes in water quality measures for seasonal time series across four sub lake areas of the northwest of Taihu during the period 2015-2019. **: $P<0.01$; *: $P<0.05$. 
(a)
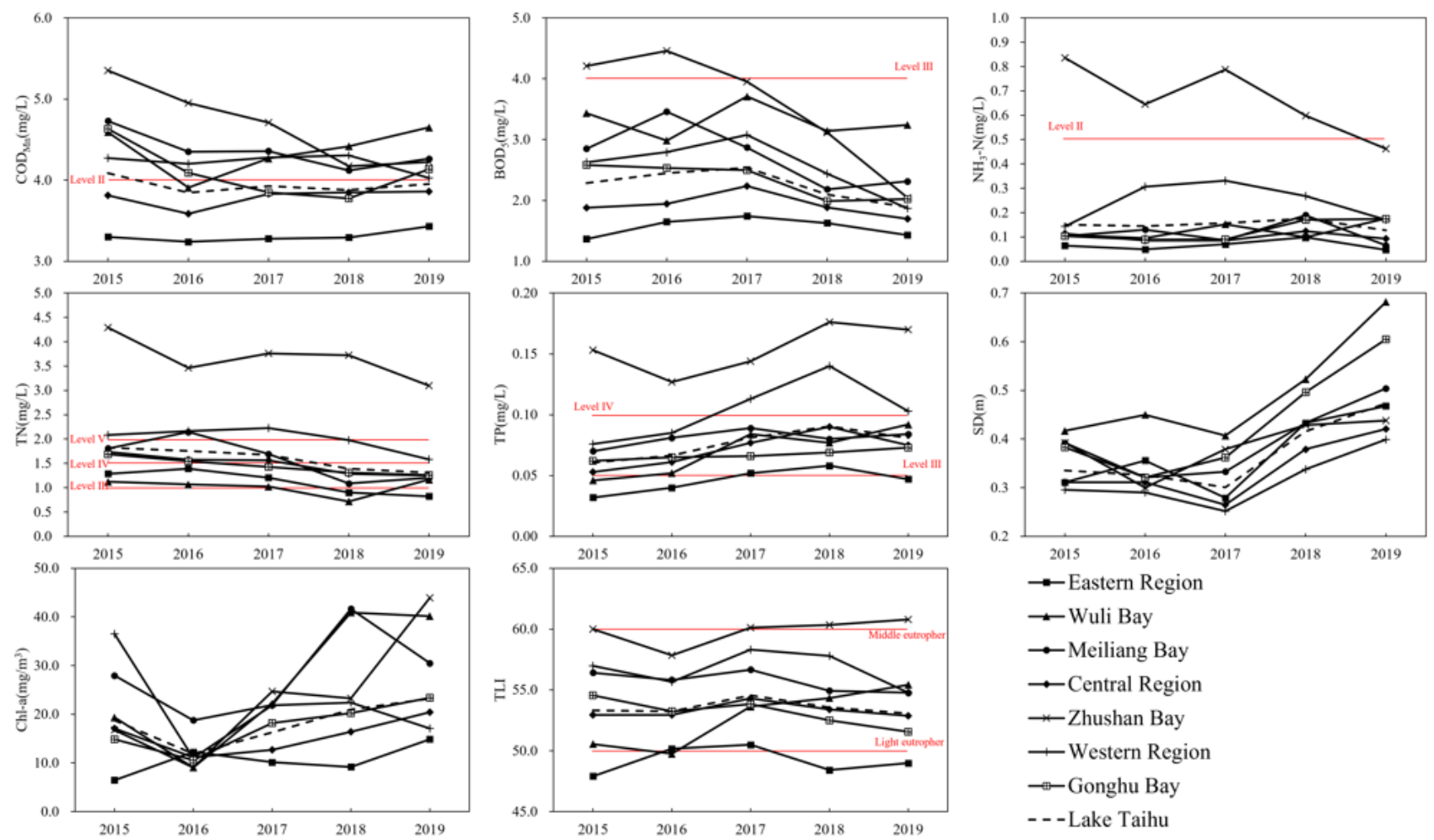

$\rightarrow$ Wuli Bay

$\rightarrow$ Meiliang Bay

$\rightarrow$ Central Region

$\rightarrow$ Zhushan Bay

-Western Region

- Gonghu Bay

- --Lake Taihu
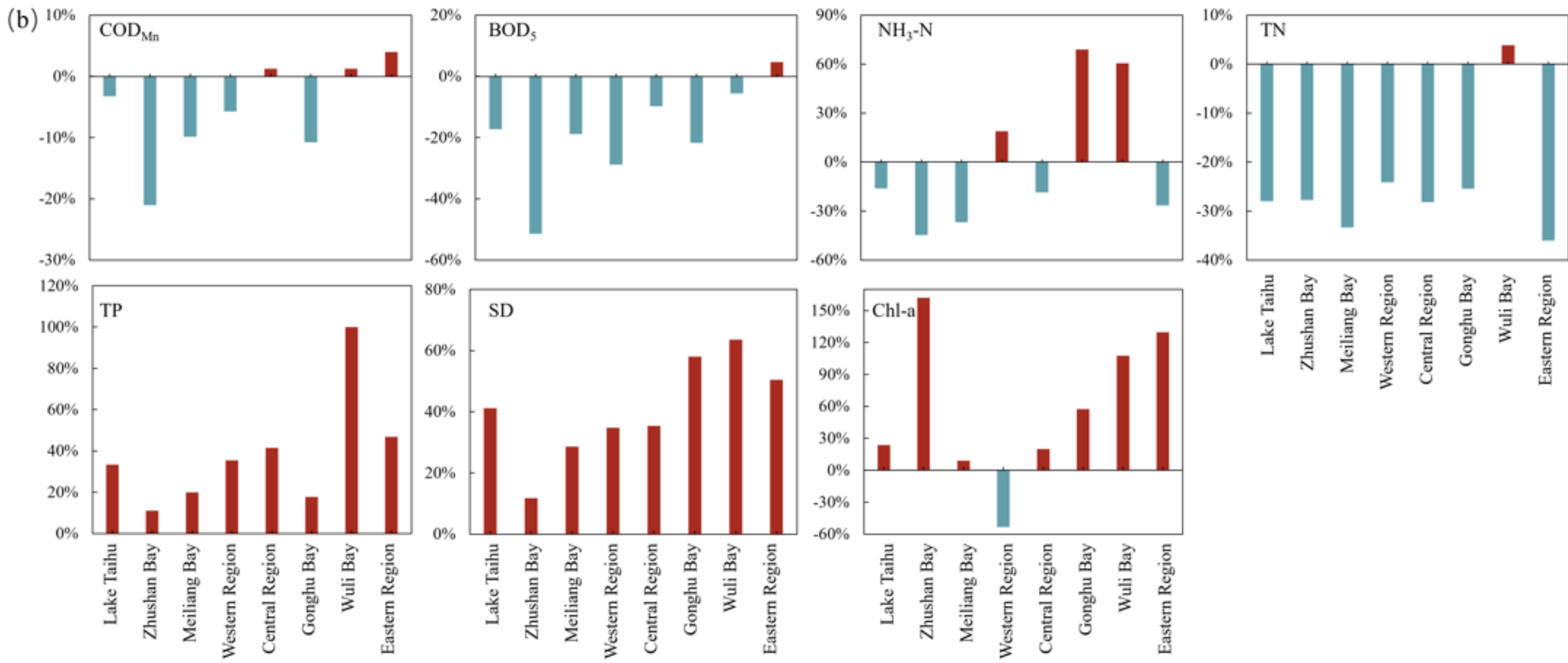

Figure 5

(a) Annual changes of water quality parameters and TLI of each sub-lakes and the Taihu from 2015 to 2019; (b) The rate of change in parameters concentration comparing 2015 with 2019. 


\begin{tabular}{|c|c|c|c|c|c|c|c|c|}
\hline Taihu & & * & & $* *$ & $* *$ & $* *$ & $*$ & \\
\hline Eastern Region & & & & $* *$ & * & $* *$ & * & \\
\hline Gonghu Bay & & * & & * & & $* *$ & * & -1.0 \\
\hline Central Region & & & & * & * & $* *$ & & \\
\hline Meiliang Bay & & $* *$ & & $* *$ & & & $* *$ & $* *: \mathrm{p}<0.01$ \\
\hline Wuli Bay & & & & & $* *$ & $* *$ & $* *$ & \\
\hline Western Region & & & & * & $* *$ & * & & \\
\hline Zhushan Bay & * & $* *$ & * & $*$ & * & & $* *$ & \\
\hline & $\underset{0}{\tilde{\Xi}}$ & $\stackrel{\overbrace{}}{0}$ & $\sum_{i}^{z_{1}}$ & ß & $\hat{F}$ & बิ & $\frac{2}{1}$ & \\
\hline
\end{tabular}

Figure 6

MK test results of long term trend for water quality parameters of Taihu from 2015 to 2019. 
(a)
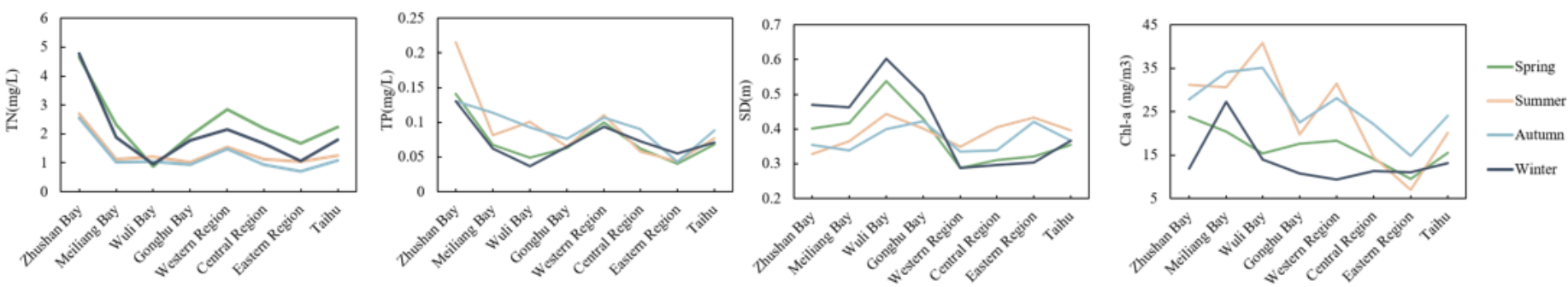

(b)

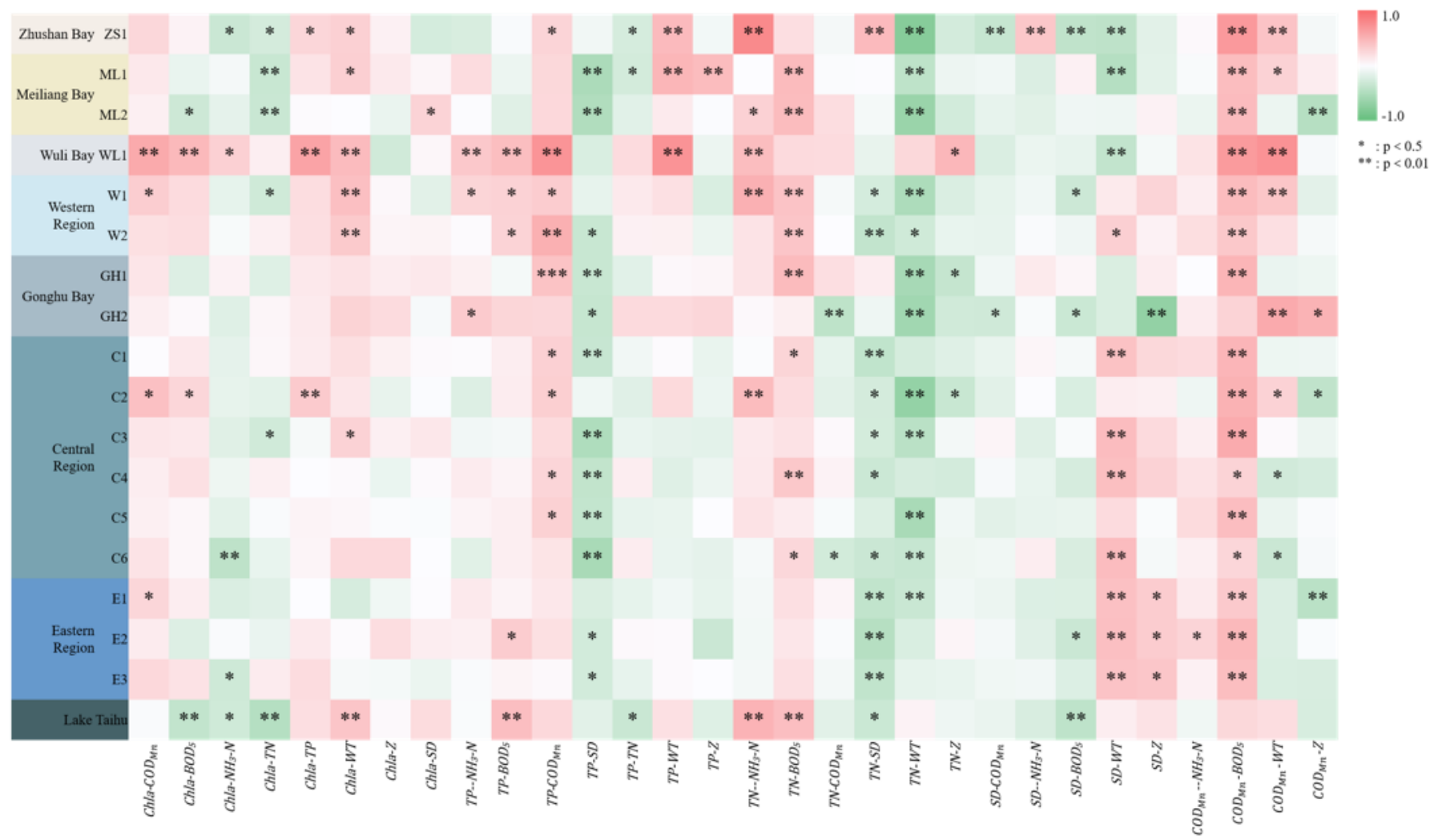

Figure 7

(a) Seasonal change of the concentrations TN, TP, SD and Chl-a. (b) Correlation statistics of quality and hydrological parameters at site-level of Taihu using monthly serial data from 2015 to 2019. 


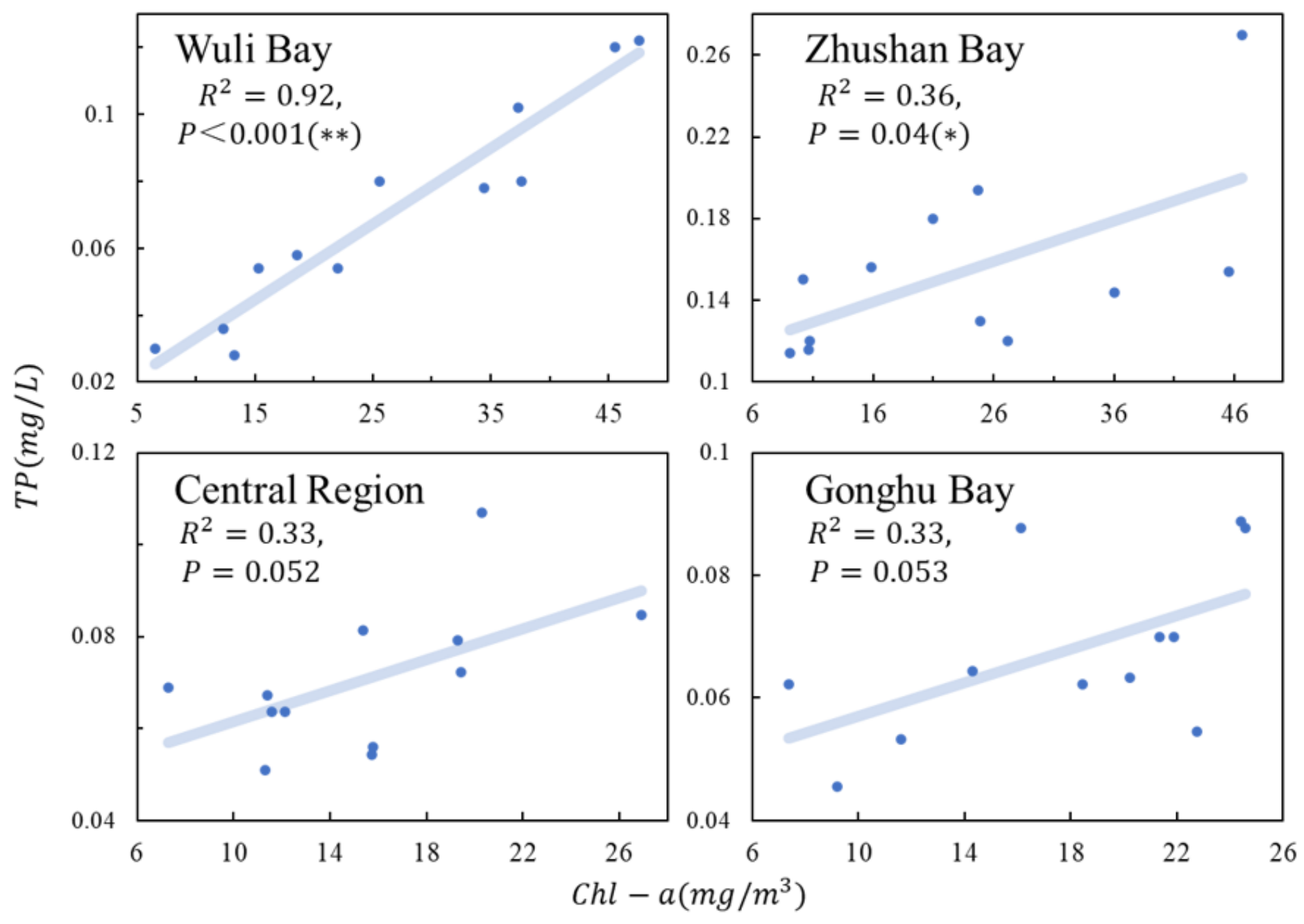

Figure 8

The correlation between monthly mean Chl-a and TP concentration in four sub-lakes. 